\title{
The William Bynum Prize - Celebration Lecture
}

'Patrick Manson and Ronald Ross: malaria and the rise and fall of a scientific friendship'

An evening lecture with Professor William Bynum: 6pm, 15 October 2013,

Bowland Auditorium, Humanities Research Centre, University of York.

This lecture celebrates the inauguration of the William Bynum Prize, an international essay competition for doctoral students and early career post-doctoral researchers. The prize, awarded to the author of an original essay on any theme relating to the history of medicine and its related sciences, is coordinated by Medical History with the generous support of Cambridge University Press. The lecture is free-of-charge, and all are warmly welcomed to attend.

Further details will be posted on the Centre for Global Health Histories' website in September - www.york.ac.uk/history/global-health-histories/events.

\section{4th American Osler Society Conference, Oxford 2014}

\author{
Sunday 11 th to Wednesday 14th May 2014 \\ plus Optional Social Programme to Friday 16th May 2014 \\ Venue: Randolph Hotel, Oxford
}

There will be attendees from USA, Canada, Australia, UK and Japan.

On Monday 12th May there will be a dinner in the Randolph Sculpture Gallery of the Ashmolean Museum.

On Tuesday 13th May there will be a dinner in a marquee outside the observatory in Green-Templeton College.

Details and booking forms to be posted on the AOS website (www.americanosler.org) in October 2013. 